\title{
Electronic Health Records in Danish Home Care and Nursing Homes: Inadequate Documentation of Care, Medication, and Consent
}

\author{
Morten Hertzum ${ }^{1}$ \\ ${ }^{1}$ Department of Communication, University of Copenhagen, \\ Copenhagen, Denmark \\ Address for correspondence Morten Hertzum, PhD, Department of \\ Communication, University of Copenhagen, Karen Blixens Plads 8, \\ Copenhagen 2300, Denmark (e-mail: hertzum@hum.ku.dk).
} Appl Clin Inform 2021;12:27-33.

\begin{abstract}
Background Electronic health records (EHRs) are used in long-term care to document the patients' condition, medication, and care, thereby supporting communication among caregivers and counteracting adverse drug events. However, the use of EHRs in long-term care has lagged behind EHR use in hospitals. In addition, most EHR research focuses on hospitals.

Objective This study gives a countrywide status of the documentation-related risks to patient safety in Danish home care and nursing homes, which are the two main providers of long-term care. Such a status provides a basis for national improvement efforts and international comparisons.

Method The study is based on the reports from 893 inspections of home care and nursing homes by the Danish Patient Safety Authority (Styrelsen for Patientsikkerhed [STPS]).

Results As much as $69 \%$ of the inspected institutions document inadequately to an extent that has led to demands (i.e., issues the institution is legally obliged to rectify) or requests (i.e., issues the institution is merely asked to rectify) from STPS. Documentation issues about the patients' condition and care are present in nearly all institutions that receive demands (97\%) and in the majority of those that receive requests (68\%). Documentation issues about medication and consent to care are also common, but less so. The predominant risk to patient safety is incomplete documentation. It covers $72 \%$ of the documentation issues identified in the institutions that received demands; the remaining risks concern inconsistent (11\%), nonexistent (7\%), inaccessible $(5 \%)$, and

Keywords

- electronic health record

- patient-safety risk

- long-term care

- home care

- nursing home noncompliant (5\%) documentation. The documentation inadequacies are similar for home care and nursing homes.

Conclusion Inadequate EHR documentation is a widespread problem in Danish longterm care. While previous research mainly focuses on how EHR documentation affects patient medication, this study finds that documentation issues about the patients' condition and care are more prevalent and that issues about their consent are also common.
\end{abstract}

received

June 9,2020

accepted

October 8, 2020 (c) 2021. Thieme. All rights reserved. Georg Thieme Verlag KG,

Rüdigerstraße 14,

70469 Stuttgart, Germany
DOI https://doi.org/

10.1055/s-0040-1721013.

ISSN 1869-0327. 


\section{Background and Significance}

The long-term care for citizens who can no longer live unassisted, mostly due to advanced age, is an extensive task in present-day health care. ${ }^{1-3}$ Many of these citizens have multiple chronic conditions and are dependent on daily medication. Their condition and care are documented in electronic health records (EHRs). In addition to medication information, EHRs for long-term care provide for extensive patient-history information, descriptive patient information, communication among diverse providers, and integrated care. ${ }^{4}$ While EHRs have been found to be "more effective than not" in long-term care settings, ${ }^{5}$ their use in these settings has lagged behind EHR use in hospitals. ${ }^{6,7}$ Furthermore, many countries have, but weak, initiatives for ensuring the safety of systems such as EHRs. ${ }^{8}$ In Denmark, EHR documentation is used throughout home care and nursing homes, which are the two main providers of long-term care, apart from relatives.

This study investigates the documentation-related risks to patient safety in Danish home care and nursing homes. These risks pertain to documentation practices that may lead to misunderstandings about the patients' condition, to medication errors, and to administering care against the patients' wishes. The documentation is made in EHRs, the use of which is mandatory. In addition, some supplementary documentation is made in paper-based records, such as medication lists kept in the patients' medication boxes. Most of the staff in long-term care is nurses, but long-term care is also provided by health care assistants (akin to nurse aides); the patients' medication is prescribed by physicians.

Home-care providers ${ }^{9-14}$ and nursing homes ${ }^{15-20}$ are in contact with citizens for much longer periods of time than hospitals, which mostly administer acute care. The long-term relationship with the patients influences the role of EHRs by increasing the importance of, for example, patient history information. ${ }^{4}$ It also calls for studies of EHR use in long-term care. The findings of these studies are mixed. ${ }^{5,21}$ Improved access, accuracy, legibility, and communication are common positive effects. $4,14,17,22$ Inadequate documentation $^{10,11,19,20,23,24}$ and lack of improvement in patient outcomes are among the shortcomings. ${ }^{14,15,18}$ Reasons for the inadequate documentation include the consumed time, ${ }^{9,25}$ insufficient staff competences, ${ }^{24,26}$ poor EHR usability, ${ }^{16,23}$ and low experienced need for EHR documentation. ${ }^{17,27}$ The low experienced need helps explain why nurses in long-term care are less positive toward the use of EHRs than nurses in hospitals. ${ }^{28}$ However, previous research does not explain how widespread the patient-safety risks associated with EHR documentation are on a national scale.

\section{Objective}

This study aims to give a countrywide status of the documentation-related risks to patient safety in Danish home care and nursing homes. Such a status is important in assessing the prevalence of the risks associated with EHR documentation, in appreciating the conditions and challenges specific to long-term care, in providing a basis for national improvement efforts, and in enabling international comparisons.

\section{Method}

The data analyzed in this study are inspection reports from the Danish Patient Safety Authority (in Danish, Styrelsen for Patientsikkerhed [STPS]). The inspection reports were analyzed using qualitative content analysis. ${ }^{29}$

\section{Danish Patient Safety Authority}

STPS is an institution under the Ministry of Health. As one of its tasks, STPS supervises health institutions in Denmark. A key instrument in this supervision is inspections, for which health institutions are selected following a risk-based strategy. That is, within each focus area (e.g., long-term care) STPS primarily conducts inspections at the institutions with a high estimated risk to patient safety. Most inspections are initiated by STPS or following up on a previous inspection, but inspections may also be conducted in response to concerns raised by citizens. A patient-safety issue central to the inspections is documentation inadequacies. There are four possible outcomes of an inspection:

Ban: the inspection has identified patient-safety issues that are so severe that the inspected institution is legally banned from providing care within a specified area until the issues have been rectified.

Demand: the inspection has identified severe patientsafety issues; the inspected institution can continue its work but is legally obliged to rectify these issues within the deadline set in the inspection report.

Request: the inspection has identified issues that negatively affect patient safety or the quality of care; the inspected institution is requested to rectify these issues within the deadline set in the inspection report.

Nothing to report: the inspection has not found issues related to patient safety and the quality of care.

All inspections are documented in reports that are openly available at https://stps.dk for 3 years. After 3 years, the reports are removed because they are no longer considered current. Reports about the same institution replace each other so that only the newest is available. That is, the reports give the current status of the inspected institutions with respect to patient-safety issues.

\section{Inspection Procedure}

An inspection is a qualitative assessment. It involves that an STPS inspector visits the institution, which is notified ahead of the visit. Each visit lasts from a couple of hours to a full day and involves a mix of:

Observation with particular focus on the practices associated with handling the patients' medication. The observation also serves to get a general sense of the quality of care.

Interviews with staff about their practices and their knowledge of procedures. Occasionally, patients or their relatives are interviewed about their experience of the care. 
Record auditing to assess whether the documentation complies with procedures and is consistent with the administered care. Typically, three patients' records are audited.

The formal documentation of an inspection is the inspection report. It contains the full list of findings and another list with the demands and requests for the rectifying actions to be taken by the institution.

\section{Data Analysis}

The inspection reports were accessed in October 2019. There were 893 reports, which covered inspections of home care and nursing homes in the period 2016 to 2019. Information about the inspection outcome (ban, demand, request, or nothing to report) was prominently displayed and easy to extract. The inspection reports were analyzed in a two-stage process of content analysis. ${ }^{29}$ Content analysis uses coding to turn qualitative data into counts of predefined categories.

First, all 893 reports were analyzed to count the number of demands and requests listed in each report and to code whether the reports contained inspection findings about risks related to the EHR documentation. The reports listed the inspection findings in a table with columns indicating (1) the inspection parameter, (2) whether it was met, and, if not, (3) a description of how the inspected institution failed to meet the parameter. The unmet parameters constituted the patient-safety risks that gave rise to demands and requests because they increased the likelihood of errors and oversights. For example, incomplete documentation of a patient's current medication increased the risk of medication errors. For each report, the set of unmet inspection parameters about EHR documentation was coded for whether it contained issues about the patients' condition and care, the patients' medication, and the patients' consent to the care. These categories emerged from an initial exploration of the inspection reports (see -Table 1 for descriptions of the categories). Once defined, the categories were used to code the reports deductively.

Second, the inspection reports that led to demands were coded in more detail. These inspections identified the most severe risks to patient safety (because no inspections led to

Table 1 Coding scheme developed for analyzing the issues reported in the inspection reports

\begin{tabular}{|c|c|c|}
\hline Category & Description & Example (translated from Danish) \\
\hline \multicolumn{3}{|l|}{ Type } \\
\hline Condition and care* & $\begin{array}{l}\text { The patient's diseases, } \\
\text { health problems, and care }\end{array}$ & $\begin{array}{l}\text { "In one of three cases, the patient history was incomplete } \\
\text { in that a blood clot in the heart, for which the patient } \\
\text { received medication, was not documented" }\end{array}$ \\
\hline Medication* & $\begin{array}{l}\text { The patient's current and } \\
\text { noncurrent medication }\end{array}$ & $\begin{array}{l}\text { "In neither of the two samples did the prescribed medi- } \\
\text { cation correspond to the list of current medication" }\end{array}$ \\
\hline Consent* & $\begin{array}{l}\text { Whether the patient has } \\
\text { given informed consent to } \\
\text { the care }\end{array}$ & $\begin{array}{l}\text { "In } 3 \text { out of } 3 \text { samples, it was not documented whether } \\
\text { informed consent had been obtained for the care" }\end{array}$ \\
\hline \multicolumn{3}{|l|}{ Risk } \\
\hline Not existing & $\begin{array}{l}\text { Documentation does not } \\
\text { exist }\end{array}$ & $\begin{array}{l}\text { "In one out of three samples, it was not possible to } \\
\text { retrieve old notes about the care for a wound. Only the } \\
\text { present plan could be retrieved as the old plan had been } \\
\text { deleted when the care plan had been changed" }\end{array}$ \\
\hline Not accessible & $\begin{array}{l}\text { Documentation is not } \\
\text { accessible }\end{array}$ & $\begin{array}{l}\text { "In connection with the implementation of a new IT } \\
\text { system, medication was administered without the pos- } \\
\text { sibility of checking the administered medication against a } \\
\text { medication list" }\end{array}$ \\
\hline Not read & Documentation is not read & No instances of this risk in the reports \\
\hline Not written / incomplete & $\begin{array}{l}\text { Documentation is not } \\
\text { written/not updated }\end{array}$ & $\begin{array}{l}\text { "In one of the samples, the problem areas had not been } \\
\text { assessed since } 2017 \text { [the inspection was made in 2019] } \\
\text { and the patient's problem with, for example, dysphagia } \\
\text { was not documented" }\end{array}$ \\
\hline Not procedure compliant & $\begin{array}{l}\text { Documentation is not com- } \\
\text { pliant with procedures }\end{array}$ & $\begin{array}{l}\text { "For one patient, an ointment was prescribed without } \\
\text { specifying which part of the body to smear and for how } \\
\text { long before contacting a doctor again" }\end{array}$ \\
\hline Inconsistent & $\begin{array}{l}\text { Documentation contradicts } \\
\text { itself }\end{array}$ & $\begin{array}{l}\text { "There were inconsistencies between the prescribed } \\
\text { medication and the medication list in } 2 \text { of } 3 \text { cases. In one } \\
\text { case, an old Marevan prescription appeared on the list of } \\
\text { current medication [...] In another case the [Marevan] } \\
\text { dosage on the medication list was not correct, even } \\
\text { though the prescription had been changed more than } \\
1 \text { week before the inspection" }\end{array}$ \\
\hline
\end{tabular}

Note: The institution-level coding of all 893 reports involved only the categories marked with an asterisk (*). The issue-level coding of the 366 issues in the reports that led to demands involved all the categories. 
bans). For this coding, all unmet inspection parameters in the tables of findings were coded individually. Each of these issues was coded for whether they were about risks related to EHR documentation. If so, their type and associated risk were also coded ( - Table 1 ). The type classification was the same as in the institution-level coding of all 893 inspections, except that the individual issues were coded rather than the entire reports. The risk classification was specific to the issue-level coding. It consisted of six categories that detailed how the issues constituted a risk to patient safety, for example, by documentation not being accessible. The coding was made by a single coder, the author.

\section{Results}

The 893 inspections covered $49 \%$ of the home-care providers and $54 \%$ of the nursing homes in Denmark. ${ }^{30}$ Because new inspections replaced older inspections of the same institution, there were more inspection reports for the most recent years: 330 (2019), 317 (2018), 200 (2017), and 46 (2016). Only 177 (20\%) of the inspections found nothing to report. As much as 681 (76\%) of them led to requests, 35 (4\%) to demands, and none to bans. The distribution was similar for home care and nursing homes. The 35 inspections that led to demands made an average of 12.34 demands and an additional 0.71 requests. The 681 inspections that led to requests made an average of 4.81 requests.

\section{Institution-Level Results}

In total, 620 (69\%) of the 893 inspection reports identified risks related to EHR documentation. More specifically, documentation issues were identified in $100 \%$ of the inspections that led to demands and in $86 \%$ of the inspections that led to requests. The documentation issues identified in inspections that led to demands as opposed to requests mostly differed in frequency; they were similar in kind. The documentation issues included that:
- Temporary staff did not have access to the EHR and, thus, had to administer care to patients without reading or updating the patient records.

- Access to an old EHR had been terminated 2 months after a new EHR was introduced without migrating records from the old to the new EHR, thereby blocking access to the patients' old records.

- The electronic records did not systematically reference the supplementary paper-based records, thereby creating considerable risk that some paper-based records went unnoticed.

- Staff was uncertain about where and how information should be recorded in a new EHR 4 months after its introduction.

- The documentation was ambiguous and unsystematic, thereby leaving the staff without an overview of the patients' condition and care.

-Table 2 shows that the documentation issues were mainly about the patients' condition and care. As much as $97 \%$ and $68 \%$ of the inspections that led to demands and requests, respectively, identified such issues. Examples included no documentation of the arrangements made with the physician responsible for a patient and the simultaneous presence of two different plans for the action to be taken on a patient's health issue. In contrast, 63\% (demands) and $46 \%$ (requests) of the inspections identified documentation issues about medication. A frequent issue was that the product name of the medication was not documented in the EHR or did not match that in the patient's medication box, thereby making it difficult for the staff to know whether the medication in the box was another product with the same content or not the right medication. Finally, 63\% (demands) and 35\% (requests) of the inspections identified that the EHR did not contain documentation of the patient's informed consent to the care. Staff is required to obtain

Table 2 Number and percentage of inspections that revealed issues about care, medication, and consent in the EHR documentation

\begin{tabular}{|c|c|c|c|c|c|c|}
\hline \multirow[t]{2}{*}{ Issue type } & \multicolumn{2}{|c|}{ Home care } & \multicolumn{2}{|c|}{ Nursing homes } & \multicolumn{2}{|c|}{ Total } \\
\hline & $N$ & $\%$ & $N$ & $\%$ & $N$ & $\%$ \\
\hline \multicolumn{7}{|l|}{ Demand reports $^{\text {a }}$} \\
\hline Condition and care & 22 & 100 & 12 & 92 & 34 & 97 \\
\hline Medication & 14 & 64 & 8 & 62 & 22 & 63 \\
\hline Consent & 15 & 68 & 7 & 54 & 22 & 63 \\
\hline \multicolumn{7}{|l|}{ Request reports $^{\mathrm{b}}$} \\
\hline Condition and care & 198 & 71 & 265 & 66 & 463 & 68 \\
\hline Medication & 138 & 50 & 178 & 44 & 316 & 46 \\
\hline Consent & 126 & 45 & 112 & 28 & 238 & 35 \\
\hline
\end{tabular}

Abbreviation: EHR, electronic health record.

${ }^{\text {a }} \mathrm{A}$ total of 22 (home care) +13 (nursing homes) $=35$ inspections led to demands.

${ }^{\mathrm{b}} \mathrm{A}$ total of 278 (home care) +403 (nursing homes) $=681$ inspections led to requests. 
Table 3 Number of documentation issues in the different risk categories (demand reports only)

\begin{tabular}{|l|l|l|l|l|l|l|l|}
\hline Issue type & $\begin{array}{l}\text { Not } \\
\text { existing }\end{array}$ & $\begin{array}{l}\text { Not } \\
\text { accessible }\end{array}$ & Not read & $\begin{array}{l}\text { Not written } \\
\text { /incomplete }\end{array}$ & $\begin{array}{l}\text { Not procedure } \\
\text { compliant }\end{array}$ & Inconsistent & Total \\
\hline Condition and care & 1 & 0 & 0 & 115 & 3 & 3 & 122 \\
\hline Medication & 0 & 3 & 0 & 7 & 7 & 19 & 36 \\
\hline Consent & 15 & 0 & 0 & 11 & 0 & 0 & 26 \\
\hline Other & 0 & 8 & 0 & 25 & 1 & 1 & 35 \\
\hline Total & 16 & 11 & 0 & 158 & 11 & 23 & 219 \\
\hline
\end{tabular}

consent whenever there are changes in the administered care. In some cases, consent had been obtained orally, but not documented. In other cases, the EHR did not contain information about whether the patients' mental state made it possible for them to give informed consent and, if not, who should do it on their behalf.

\section{Issue-Level Results}

The 35 inspections that led to demands identified 366 issues. As much as $219(60 \%)$ of these issues related to EHR documentation. -Table 3 shows the distribution of the 219 documentation issues across risk categories. The majority of the risks concerned that documentation was not written or remained incomplete (158 issues, i.e., $72 \%$ ). This risk category was by far the most frequent for the issues about the patients' condition and care. For example, an issue stated that adequate documentation of the patient's diseases and disabilities was missing in all three audited records. For medication, the most frequent risk category was inconsistent documentation (19 issues, i.e., 53\%). For example, an issue stated that the prescribed medication did not match the current medication for any of the patients whose records were audited. One patient's records contained multiple, nonidentical lists of the current medication. For consent, the risks were distributed between documentation that was incomplete (42\%) and did not exist at all (58\%). While fairly few issues were about consent, these issues were spread across many inspections and thus occurred in many institutions. Finally, there were 11 cases in which entire staff groups, typically the temporary staff, did not have access to the EHR.

\section{Discussion}

In spite of their EHRs, the inspected home-care providers and nursing homes face considerable documentation challenges. Six findings stand out:

First, inadequate EHR documentation is a common challenge in Danish long-term care. As much as 69\% of the 893 inspected institutions document inadequately to an extent that has led to demands or requests from STPS. This finding substantiates previous findings of incomplete EHR documentation in long-term care. ${ }^{11,19,31}$ The documentation issues underscore that the patient-safety risks associated with EHR documentation are about the interrelations be- tween the EHRs and their use context, such as inconsistencies between the documentation and the actual content of the patients' medication boxes. The reasons for the documentation issues may, for example, be workarounds that are employed to be efficient, including that home-care nurses write on paper then transfer to the EHR, avoid charting at the point of care, and complete tasks before they document. ${ }^{12}$ In addition, documentation issues may emerge because caregivers in long-term care experience little need for documentation ${ }^{17}$ and prefer other information sources. ${ }^{27}$

Second, the documentation issues for both home care and nursing homes are primarily about the patients' condition and care and only secondarily about their medication. This finding extends previous studies, which predominantly focus on how EHRs affect patient medication. ${ }^{4,23}$ However, previous studies of care plans support that without adequate documentation of the patients' condition, there is increased risk of errors and oversights in the administered long-term care. ${ }^{19}$ For example, EHRs have an important role in communicating the information about a patient's condition and care among all those involved in caring for the patient. ${ }^{32}$

Third, documentation issues about medication are present in $63 \%$ and $46 \%$ of the institutions that receive demands and requests, respectively. The reasons for the high incidence of these issues include that patients in long-term care take multiple medications, which over time are prescribed and replaced by different physicians. A typical nursing home patient takes about six different medications daily, with more than $20 \%$ taking 10 or more medications per day. ${ }^{4}$ There is a large need for better documentation and management of this medication. For example, Bao et $\mathrm{al}^{33}$ find that $38 \%$ of home-care recipients take at least one potentially inappropriate medication. Consistent with this finding, the documentation issues about medication provide evidence of incompleteness, inconsistency, and noncompliance with procedures.

Fourth, consent is inadequately documented. In $63 \%$ and $35 \%$ of the institutions that receive demands and requests, respectively, it is not consistently documented that the patients have consented to their care. In the previous studies of EHRs in long-term care, consent is only mentioned peripherally in the form of patient wishes regarding lifesustaining care. ${ }^{22}$ Such wishes are a prime example of consent and illustrate its importance in avoiding that patients risk being treated in a way or at a time that they 
do not consider right. In Denmark, patients must give consent to all changes in their care. This requirement is meant to underscore that the patients are the final arbiters on matters relating to their life and care. Failing to document that consent has been obtained does not necessarily mean that the staff has not obtained consent orally, but the frequency with which consent is not documented suggests that the staff, on occasion, pay scant attention to consent.

Fifth, the distribution of the documentation-related risks to patient safety is similar for home-care and nursing homes. It appears that the shared context of long-term care creates many similarities. The only sizable difference is that documentation issues about consent are more frequent for homecare $(45 \%)$ than nursing homes (28\%). Previous studies have emphasized that home-care providers are mobile ${ }^{13}$ and work alone during patient visits, ${ }^{11}$ whereas nursing homes provide a shared physical location. These conditions could increase the need for home-care EHRs to facilitate communication among caregivers. However, mobile technologies are also reported to benefit nursing homes ${ }^{34}$ and so is EHR support for communication. ${ }^{16}$ Thus, previous studies support the finding of similar results for home care and nursing homes.

Sixth, the findings are specifically about EHR documentation in long-term care, which differs from acute care. The long-term perspective instills a focus on caring and gradual deterioration rather than on restoring to health. As a consequence, records in long-term care tend to be textual, particularly with respect to the evolution in the patients' condition and care. ${ }^{4,19}$

Three limitations should be remembered in interpreting the results of this study. First, the study is about long-term care in Denmark. An aging population is not specific to Denmark, but the organization of the health care system is. Other countries may experience another mix of documentation-related risks in their institutions for long-term care. Second, STPS's risk-based strategy for selecting institutions for inspection means that institutions with a high likelihood of risks to patient safety are probably overrepresented. That said, the sample size of 893 institutions prevents that a few outliers skew the results. Third, the coding of the inspection reports has not been validated by comparing it with another coder's independent coding. While this precludes intercoder statistics, each documentation issue has instead been described and coded by two different people-the inspector and author, respectively. This separation bolsters the quality of the analysis by providing an independent basis for the coding.

\section{Conclusion}

The status across 893 Danish institutions for long-term care is that $69 \%$ display documentation-related risks to patient safety. The documentation issues for both home care and nursing homes are first about the patients' condition and care, second about their medication, and third about their consent. This distribution differs from previous research, which gives precedence to documentation issues about medication. While the risk associated with the majority of the issues is incomplete documentation, there are also instances of self-contradictory documentation and of caregivers without EHR access.

It is hoped that this study will help in assessing the risks associated with EHR documentation, appreciating the challenges specific to long-term care, guiding national improvement efforts, and enabling international comparisons. To meet this larger objective, future work must complement counts of documentation inadequacies with analyses of their clinical relevance.

\section{Clinical Relevance Statement}

Inadequate EHR documentation poses patient-safety risks in $69 \%$ of Danish home care and nursing homes. Nursing-home and home-care staff should devote additional attention to the documentation of the patients' condition and care, their medication, and their consent. Staff, patients, and relatives cannot assume that the EHR documentation is complete but need to engage in oral follow-ups to ensure the quality of care.

\section{Multiple Choice Questions}

1. In long-term care, what are documentation inadequacies primarily about?

a. Patients' condition and care.

b. Patients' medication.

c. Patients' consent to care.

d. None of the above.

Correct Answer: The correct answer is option a, see - Tables 2 and 3.

2. What is the risk most frequently associated with inadequate documentation of medication?

a. The documentation is not accessible.

b. The documentation is incomplete.

c. The documentation is inconsistent.

d. The documentation is not procedure compliant.

Correct Answer: The correct answer is option c, see - Table 3.

Protection of Human and Animal Subjects

This study analyzes publicly available documents. It does not include human or animal subjects.

Funding

None.

Conflict of Interest

None declared.

\section{References}

1 Harris-Kojetin L, Sengupta M, Lendon JP, Rome V, Valverde R, Caffrey C. Long-term care providers and services users in the United States, 2015-2016. Vital Health Stat 2019;3(43):1-78 
2 Leichsenring K, Billings J, Nies H, eds. Long-Term Care in Europe: Improving Policy and Practice. New York: Palgrave Macmillan; 2013

3 Lum T. Long-term care in Asia. J Gerontol Soc Work 2012;55(07): 563-569

4 Phillips K, Wheeler C, Campbell J, Coustasse A. Electronic medical records in long-term care. J Hosp Mark Public Relations 2010;20 (02):131-142

5 Kruse CS, Mileski M, Vijaykumar AG, Viswanathan SV, Suskandla U, Chidambaram Y. Impact of electronic health records on longterm care facilities: systematic review. JMIR Med Inform 2017;5 (03):e35

6 Bjarnadottir RI, Herzig CTA, Travers JL, Castle NG, Stone PW. Implementation of electronic health records in U.S. nursing homes. Comput Inform Nurs 2017;35(08):417-424

7 Heimly V, Grimsmo A, Faxvaag A. Diffusion of electronic health records and electronic communication in Norway. Appl Clin Inform 2011;2(03):355-364

8 Magrabi F, Aarts J, Nøhr C, et al. A comparative review of patient safety initiatives for national health information technology. Int J Med Inform 2013;82(05):e139-e148

9 De Vliegher K, Paquay L, Vernieuwe S, Van Gansbeke H. The experience of home nurses with an electronic nursing health record. Int Nurs Rev 2010;57(04):508-513

10 Gershater MA, Pilhammar E, Roijer CA. Documentation of diabetes care in home nursing service in a Swedish municipality: a cross-sectional study on nurses' documentation. Scand J Caring Sci 2011;25(02):220-226

11 Gjevjon ER, Hellesø R. The quality of home care nurses' documentation in new electronic patient records. J Clin Nurs 2010;19(12):100-108

12 Ibrahim S, Donelle L, Regan S, Sidani S. A qualitative content analysis of nurses' comfort and employment of workarounds with electronic documentation systems in home care practice. Can J Nurs Res 2020;52(01):31-44

13 Nilsson M, Hertzum M. Negotiated rhythms of mobile work: time, place, and work schedules. In: Proceedings of the GROUP2005 Conference on Supporting Group Work. New York: ACM Press; 2005: 148-157

14 Sockolow PS, Bowles KH, Adelsberger MC, Chittams JL, Liao C. Challenges and facilitators to adoption of a point-of-care electronic health record in home care. Home Health Care Serv Q 2014; 33(01):14-35

15 Hitt LM, Tambe P. Health care information technology, work organization, and nursing home performance. Ind Labor Relat Rev 2016;69(04):834-859

16 Meehan R. Electronic health records in long-term care: staff perspectives. J Appl Gerontol 2017;36(10):1175-1196

17 Munyisia EN, Yu P, Hailey D. The changes in caregivers' perceptions about the quality of information and benefits of nursing documentation associated with the introduction of an electronic documentation system in a nursing home. Int J Med Inform 2011; 80(02):116-126
18 Pillemer K, Meador RH, Teresi JA, et al. Effects of electronic health information technology implementation on nursing home resident outcomes. J Aging Health 2012;24(01):92-112

19 Tuinman A, de Greef MHG, Krijnen WP, Paans W, Roodbol PF. Accuracy of documentation in the nursing care plan in long-term institutional care. Geriatr Nurs 2017;38(06):578-583

20 Voyer P, McCusker J, Cole MG, et al. Nursing documentation in long-term care settings: new empirical evidence demands changes be made. Clin Nurs Res 2014;23(04):442-461

21 Yu P, Zhang Y, Gong Y, Zhang J. Unintended adverse consequences of introducing electronic health records in residential aged care homes. Int J Med Inform 2013;82(09):772-788

22 Shiells K, Holmerova I, Steffl M, Stepankova O. Electronic patient records as a tool to facilitate care provision in nursing homes: an integrative review. Inform Health Soc Care 2019;44(03):262-277

23 Qian S, Yu P, Hailey DM. The impact of electronic medication administration records in a residential aged care home. Int J Med Inform 2015;84(11):966-973

24 Wang N, Yu P, Hailey D. The quality of paper-based versus electronic nursing care plan in Australian aged care homes: a documentation audit study. Int J Med Inform 2015;84(08): 561-569

25 Munyisia EN, Yu P, Hailey D. Does the introduction of an electronic nursing documentation system in a nursing home reduce time on documentation for the nursing staff? Int J Med Inform 2011;80 (11):782-792

26 Cheevakasemsook A, Chapman Y, Francis K, Davies C. The study of nursing documentation complexities. Int J Nurs Pract 2006;12 (06):366-374

27 Østensen E, Bragstad LK, Hardiker NR, Hellesø R. Nurses' information practice in municipal health care-a web-like landscape. J Clin Nurs 2019;28(13-14):2706-2716

28 de Veer AJE, Francke AL. Attitudes of nursing staff towards electronic patient records: a questionnaire survey. Int J Nurs Stud 2010;47(07):846-854

29 Hsieh H-F, Shannon SE. Three approaches to qualitative content analysis. Qual Health Res 2005;15(09):1277-1288

30 Danish Patient Safety Authority. Available at: https://stps.dk. Accessed November 18, 2019

31 Wang N, Yu P, Hailey D. Description and comparison of documentation of nursing assessment between paper-based and electronic systems in Australian aged care homes. Int J Med Inform 2013;82 (09):789-797

32 Zhang Y, Yu P, Shen J. The benefits of introducing electronic health records in residential aged care facilities: a multiple case study. Int J Med Inform 2012;81(10):690-704

33 Bao Y, Shao H, Bishop TF, Schackman BR, Bruce ML. Inappropriate medication in a national sample of US elderly patients receiving home health care. J Gen Intern Med 2012;27(03):304-310

34 Jones W, Drake C, Mack D, Reeder B, Trautner B, Wald H. Developing mobile clinical decision support for nursing home staff assessment of urinary tract infection using goal-directed design. Appl Clin Inform 2017;8(02):632-650 